\title{
USO DA TAXONOMIA COMO FERRAMENTA DE REDUÇÃO DA SUBJETIVIDADE NOS PROCESSOS DE AUDITORIA
}

\author{
José Humberto da Cruz Cunha ${ }^{I}$ \\ Rogério Henrique de Araújo Junior ${ }^{I I}$ \\ ${ }^{I}$ Universidade de Brasília, Brasília, DF, Brasil. \\ Doutorando em Ciência da Informação. \\ Professor do Departamento de Ciências Contábeis.

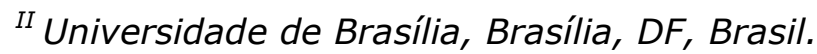 \\ Doutor em Ciência da Informação. \\ Professor da Faculdade de Ciência da Informação.
}

http://dx.doi.org/10.1590/1981-5344/3174

Trata da viabilidade de elaboração de uma taxonomia de distorções contábeis como ferramenta para a redução da subjetividade nos processos de auditoria. Os riscos de distorção contábil são mapeados na literatura e então classificados na estrutura taxonômica. O caminho entre a análise desses riscos e a escolha de procedimentos de auditoria formam uma rota objetiva fundamentada por relações lógicas conceituais. Configura-se como um estudo qualitativo exploratório que tem como procedimentos metodológicos o levantamento bibliográfico e a pesquisa documental para subsidiar as análises qualitativas. A análise de conteúdo foi aplicada em documentos obtidos junto ao caso de estudo no Tribunal de Contas da União (TCU). Os resultados obtidos indicam a funcionalidade da taxonomia como instrumento auxiliar às decisões dos auditores para a escolha de procedimentos a partir da classificação de risco de distorções provenientes de erros e fraudes. Na sequência lógica desse processo ficam evidenciadas rotas objetivas caracterizadas como trilhas de auditoria, sugerindo a redução da subjetividade nas escolhas do auditor. 
Palavras-chave: Linguagem documentária; Taxonomia; Recuperação da informação; Auditoria contábil; Distorção contábil; Risco.

\section{USE OF TAXONOMY AS TOOL TO REDUCE THE AUDIT PROCESS SUBJECTIVE ASPECTS}

This is a study about a taxonomy of financial statement distortions development as tool to reduce subjective aspects on audit process by an application case for studying. Distortion accounting risks are mapped based on accounting literature and classified on taxonomy structure. The way between a risk analysis and procedures choosing is an objective route that makes a logical relationship conceptual support. This is a qualitative and exploratory study that has a bibliography and a documental research as technical procedures supporting its qualitative analysis. A content analysis is applied on given documents by an independent public institution called Tribunal de Contas da União (TCU), which one is responsible for auditing on Brazilian Federal Government statements. The results show a taxonomy function as an auxiliary instrument for auditor's decisions making originated on errors and frauds. Then, the logical procedure indicates objective routes as an audit trails suggesting a subjectivity reduction on auditor's procedures decisions.

Keywords: Documentary language; Taxonomy; Information retrieval; Audit; Accounting Distortion; Risk.

Recebido em 01.06.2017 Aceito em 02.04.2019

\section{Introdução}

Ao longo do processo de auditoria contábil, entre a análise de risco e escolha de procedimentos há aspectos subjetivos que podem enviesar a escolha, a aplicação ou a interpretação desses procedimentos. (CHANG et al, 2008). Entretanto, na Ciência da Informação (CI) as linguagens documentárias auxiliam na redução da subjetividade e na recuperação de informações a partir da padronização e classificação da linguagem natural (SOUSA; ARAÚJO JÚNIOR, 2013). Nesse sentido, a questão problema é: há viabilidade na utilização de uma taxonomia de distorções contábeis 
como ferramenta para a redução da subjetividade nos processos de auditoria?

$\mathrm{Na}$ auditoria contábil há subjetividade na rotina de avaliação e escolha dos procedimentos a serem aplicados pelo auditor (análise de alternativas) determinada pela observação das consequências (erros observados) frente ao conjunto de critérios de avaliação - afirmações e fundamentos das etapas do processo de auditoria (BOYNTON; JOHNSON; KELL, 2002; LONGO, 2011).

$\mathrm{Na} \mathrm{CI}$, o emprego de linguagens documentárias permite a padronização no uso de termos de indexação, por meio da sumarização do conteúdo dos documentos ou itens de informação, a fim de viabilizar a recuperação da informação. Pressupõe-se, então, que a taxonomia, como uma linguagem documentária, pode auxiliar a auditoria contábil na recuperação da informação, o que por sua vez, otimizará toda a atividade. Sendo assim, o objetivo do artigo é estudar e viabilidade de construção de uma taxonomia de distorções contábeis como ferramenta para a redução da subjetividade nos processos de auditoria.

O estudo é exploratório, de natureza qualitativa e adotou como procedimentos técnicos para a proposição da taxonomia, levantamento bibliográfico e pesquisa documental. Os riscos de distorções contábeis foram mapeados na literatura contábil e classificados na estrutura taxonômica e a viabilidade de aplicação da taxonomia foi verificada, por meio da análise de documentos obtidos junto ao Tribunal de Contas da União (TCU), comparando as decisões no relatório de auditoria com a estrutura conceitual da taxonomia nos aspectos de divergências e convergências.

\section{Referencial teórico}

A linguagem documentária destina-se a expressar o conteúdo semântico em uma linguagem especializada com foco na recuperação de informações. A linguagem natural contém problemas diversos como imprecisão e ambiguidade de palavras, além de impor obstáculos ao armazenamento e a recuperação da informação (SOUSA; ARAÚJO JÚNIOR, 2013).

Segundo Guedes e Araújo Júnior (2014), as características da linguagem documentária permitem a organização das informações em um sistema de modo a facilitar a interrogação e busca. Esta é a etapa na qual se dá a interação entre o estoque de dados e informações com os usuários. Nesse estudo foram identificados ruídos na comunicação no processo de auditoria em que os usuários são os próprios auditores contábeis. Ao analisar a literatura na CI e a literatura da área contábil fica claro que há subjetividade nesse processo e que as linguagens documentárias podem ser uma possibilidade de reduzir redundâncias, inconsistências e imprecisão, questões que podem influenciar diretamente a análise de risco de auditoria.

Considerando que a execução do trabalho enseja uma série de procedimentos para minimizar os riscos, a análise de riscos e a aplicação 
de procedimentos são etapas fundamentais na execução da tarefa, vinculadas e dependentes entre si (CASTRO, 2010; BOYNTON; JONHNSON; KELL, 2002; AICPA, 2012). Entretanto, a seleção, a interpretação e a aplicação dos procedimentos, segundo Loughran (2010), encerram subjetividades provenientes do auditor, manifestadas através da linguagem natural, o que pode trazer distorções nas conclusões da auditoria (GUEDES; ARAÚJO JÚNIOR, 2014).

Uma parte das informações a serem acessadas pelos auditores constituem-se em lições aprendidas de trabalhos anteriores, que nessa investigação são classificadas na estrutura da taxonomia. Tais informações apontam para os riscos de distorções contábeis provenientes de erros ou fraudes. Na área de negócios, as lições aprendidas são comumente utilizadas em gerenciamento de projetos (CHAN, 2012). Por sua vez, as taxonomias têm se constituído em um campo profícuo de pesquisas e estudos aplicados à gestão da informação em bases de dados e de conhecimento, voltadas para subsidiar o processo de tomada de decisão (WALDEN, 2007; MILNE, 2007; GIESS et al, 2009; HSIAO, 2011).

Diante das inúmeras possibilidades de arranjos das lições aprendidas, a estrutura da taxonomia proposta fundamenta-se na classificação facetada proposta por Ranganathan (2006) e Vickery (1960), combinada com as relações lógicas apresentadas na Teoria do Conceito de Dahlberg (1978). As conexões entre as facetas formam caminhos para as decisões padronizadas em linguagem documentária pela relação aspecto conceitual. Esta relação pode ser denominada de trilha ou processo com lastro informacional.

Assim, a trilha de auditoria consiste em um histórico de todas as intervenções feitas no documento ou no próprio sistema de gerenciamento de documentos e objetiva "assegurar que as informações estejam disponíveis para a inspeção, a fim de que uma ocorrência específica possa ser identificada e que todas as respectivas informações sejam claras e compreensíveis" (CNJ, 2009).

A relação entre a trilha de auditoria e a linguagem documentária se dá por meio da estrutura da taxonomia proposta, por meio de relações lógico-conceituais onde as etapas de execução e as lições aprendidas sobre erros e fraudes em linguagem natural do auditor são condensadas e padronizadas em linguagem documentária. Além disso, a estrutura taxonômica permite a classificação de erros e fraudes (lições aprendidas), possibilitando a recuperação de informações para a análise de riscos e escolha de procedimentos a partir de uma linguagem padronizada.

\section{Metodologia}

A pesquisa reúne informações, padrões e ideias sobre um problema com pouco ou nenhum estudo anterior. Entretanto, não foca em teste de hipóteses, mas procura padrões com respostas para determinados problemas e indicação de pesquisas futuras (MUELLER, 2007). Inicialmente, tem-se o desenvolvimento da taxonomia na auditoria contábil e posteriormente a análise dos resultados com sua aplicação. 
O desenvolvimento da taxonomia de distorções contábeis se concretizou mediante pesquisa bibliográfica com levantamento dos aspectos conceituais que permitiram a tradução da linguagem na literatura da área contábil para uma linguagem documentária nos moldes do arcabouço teórico da ciência da informação. Assim, a elaboração da estrutura taxonômica foi calcada em etapas metodológicas apresentadas por Vital e Café (2007).

A análise do processo de auditoria deu-se a partir do levantamento bibliográfico (AICPA, 2012; BOYNTON; JOHNSON; KELL, 2002; GAO, 1996), durante a etapa de diagnóstico, focando no entendimento de quais aspectos são mais importantes na identificação de distorções contábeis com atribuição dos termos que as representam em termos documentários. Durante a pesquisa, observou-se que as informações contábeis possuem um conceito mais abrangente e posicionam-se como o ponto focal para análise de riscos e aplicação de procedimentos. Sendo assim, a expressão "informações contábeis" é identificada como o gênero para a estrutura de classificação desenvolvida.

O Quadro 1 apresenta as facetas que representam o processo de auditoria desde as etapas de análise de risco até a escolha e aplicação dos procedimentos, além de apresentar um extrato da composição da taxonomia desenvolvida.

Quadro 1 - Facetas e seus conceitos na taxonomia de distorções contábeis.

\begin{tabular}{|c|c|c|}
\hline \multirow{7}{*}{ 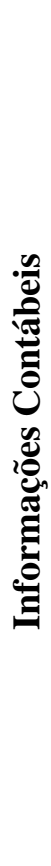 } & Facetas & Termos \\
\hline & $\begin{array}{l}\text { Fases da informação: informações contábeis } \\
\text { relacionadas às fases de reconhecimento, } \\
\text { mensuração e evidenciação. }\end{array}$ & Reconhecimento; Mensuração; Evidenciação. \\
\hline & $\begin{array}{l}\text { Aspectos essenciais: características comuns que } \\
\text { representam a essência de todas as distorções } \\
\text { levantadas. }\end{array}$ & Patrimônio; Documento suporte; Valor; Registro. \\
\hline & $\begin{array}{l}\text { Afirmações: aspectos associados às informações } \\
\text { contábeis testadas pelos auditores. }\end{array}$ & $\begin{array}{l}\text { Existência/Ocorrência; Direitos/Obrigações; } \\
\text { Avaliação/Alocação; Apresentação/Divulgação; } \\
\text { Corte; Integridade. }\end{array}$ \\
\hline & $\begin{array}{l}\text { Procedimentos: testes substantivos aplicados pelo } \\
\text { auditor para coleta e análise de riscos de distorções. }\end{array}$ & $\begin{array}{l}\text { Confirmação; Inspeção; Vouching; Recálculo; } \\
\text { Rastreamento; Corte; Reconciliação. }\end{array}$ \\
\hline & $\begin{array}{l}\text { Ciclos de recursos: categoria que classifica as } \\
\text { informações em entradas e saídas econômicas e/ou } \\
\text { financeiras. }\end{array}$ & Obtenção de recursos; Utilização de recursos. \\
\hline & $\begin{array}{l}\text { Subciclos de recursos: subcategorias dos ciclos de } \\
\text { recursos utilizadas em uma estrutura contábil } \\
\text { abrangendo as informações contábeis. }\end{array}$ & $\begin{array}{l}\text { Atividades operacionais; Atividades de } \\
\text { financiamento; Atividades de investimento. }\end{array}$ \\
\hline
\end{tabular}

Fonte: Elaborado pelos autores.

Considerando a relação entre a Ciência da Informação e a Ciência Contábil os níveis de relacionamento entre os termos da taxonomia seguiram o seguinte entendimento: 
- Cada termo é associado a outros que estão na mesma unidade de classificação e no mesmo ramo temático e de conhecimento;

- Outras linguagens documentárias, baseadas em terminologias específicas, distribuem por ramos do conhecimento a relação hierárquica entre os termos; e

- A taxonomia é a base de descritores onde estão listados os grandes temas tratados na atividade para a qual foi criada.

Além disso, os níveis de relacionamentos entre os termos estão baseados na seguinte lógica de representação (BRANDES, 2007):

I) Relação de equivalência: devem ser usadas notações que caracterizem a relação de equivalência entre os termos da taxonomia. As notações empregadas são:

- USE/NÃO USE: notação empregada para indicar o "termo" autorizado para uso; e

- UP: notação empregada para indicar "utilizado para". Tem como finalidade indicar o "termo" não autorizado e apontar para o "termo" autorizado. As relações de equivalência representadas por USE/NÃO USE e UP são chamadas de remissivas;

II) Relação hierárquica: devem ser usadas notações que caracterizem a relação hierárquica entre os termos da taxonomia. As notações empregadas são:

- TG: notação utilizada para indicar "Termo Genérico". É empregada para exprimir uma relação que indica o termo hierárquico superior. De outra maneira, indica um "termo" mais abrangente; e

- TE: notação que aponta para "Termo Específico". Deve ser usada para exprimir uma relação que indica o termo hierárquico inferior. De outra maneira, indica "termos" mais definidos.

III) Relação de associação: deve ser usada uma notação que caracterize uma relação semântica, partitiva e associativa não hierárquica. A notação utilizada foi:

- TR: notação que indica "Termo Relacionado". Deve ser usada para exprimir a associação entre um "termo" relacionado semanticamente com outro "termo" sem qualquer relação de subordinação entre eles.

A Figura 1 apresenta como ocorre a ordem de utilização com base nessas relações entre termos da taxonomia. 
Figura 1 - Relação de equivalência na faceta de fases da informação

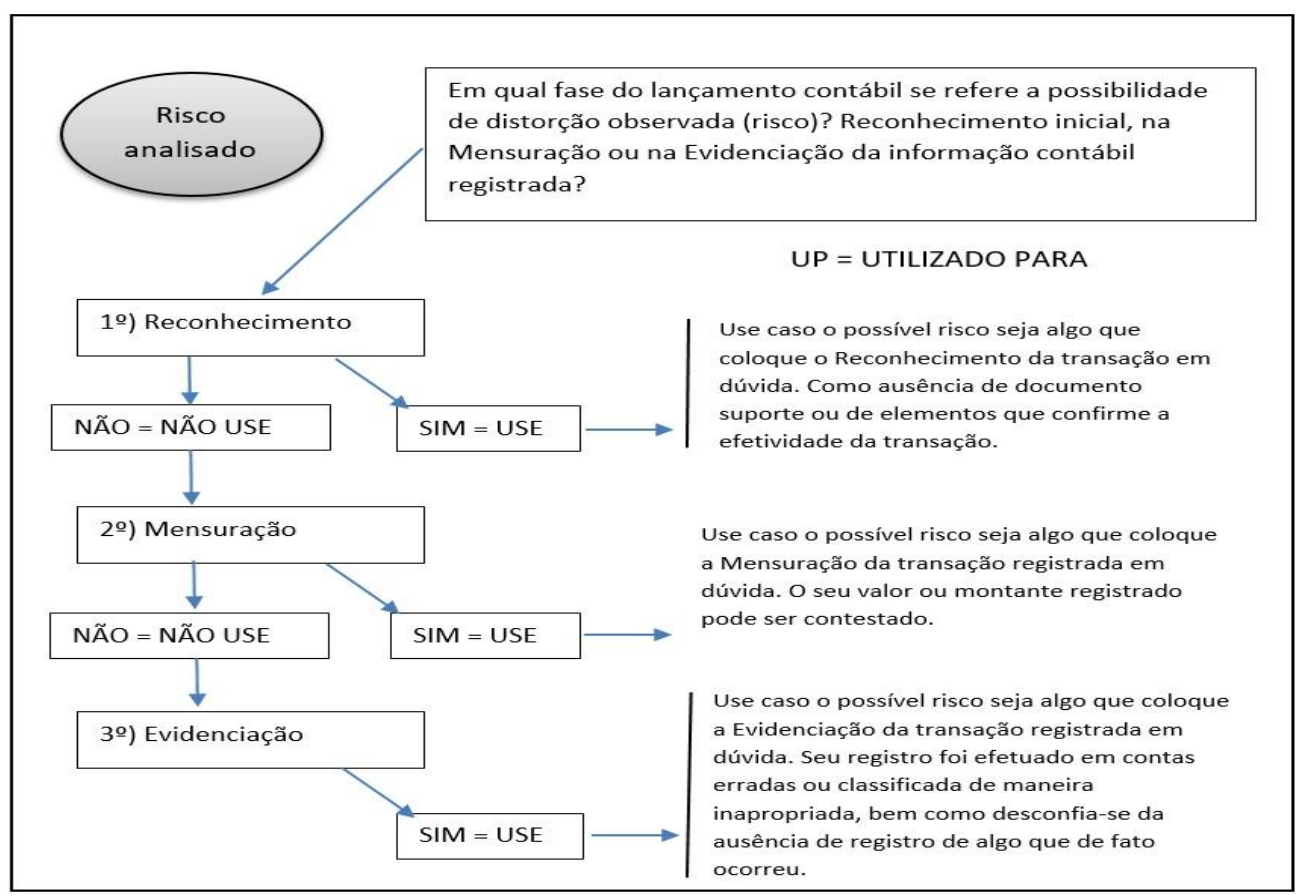

Fonte: Elaborado pelos autores

Após o desenvolvimento da taxonomia, houve a aplicação na análise de documentos de um processo de auditoria contábil do Tribunal de Contas da União (TCU), órgão responsável pela auditoria das contas do Governo brasileiro. O processo TC-031.235-2015-8, cedido para essa investigação, é um dos dois primeiros que o Tribunal executou alinhado com as normas internacionais de auditoria focada em demonstrações financeiras.

A técnica utilizada foi a análise de conteúdo, que pode ser conceituada como um conjunto de técnicas com etapas de execução adaptáveis a um campo de aplicação específico (BARDIN, 1977). Além disso, uma codificação nesse tipo de análise deve apresentar "consistência e aceitabilidade ao ser aplicada aos diferentes documentos para que proporcione confiança nas análises comparativas" (GAO, 1996).

Tendo como base os autores citados, as principais etapas da análise de conteúdo adotadas foram:

(a) Análise inicial, com leitura preliminar e delimitação do espaço a ser analisado;

(b) Identificação de termos e expressões a serem buscados; e

(c) Interpretação dos dados.

Durante a análise de conteúdo fez-se uma leitura preliminar, definindo como foco duas espécies de documentos apensados ao processo de auditoria do TCU: 
(1) Matriz de Avaliação de Riscos - Fundo do Regime Geral de Previdência Social (FRGPS) - Despesas previdenciárias; e

(2) Matriz de planejamento dos procedimentos.

No processo, três elementos foram selecionados para a coleta de dados: (a) Atributos relacionados à análise dos riscos de distorções contábeis, provenientes de erros ou fraudes, (b) Afirmações de auditoria e (c) Procedimentos, assim como as áreas contábeis para sua aplicação. Esses elementos são importantes na estrutura conceitual da taxonomia e esperados dentro de processos de auditoria que estão em conformidade com as normas internacionais.

\section{Análises dos resultados}

A taxonomia proposta contém um conjunto de termos que representa o processo de auditoria. A Figura 2 exibe todos os termos e as formas como estão relacionados. As relações facetadas demonstradas permitem uma flexibilidade ao interagirem com os termos imediatamente anteriores e posteriores nessas relações, porém limitadas às relações lógicas da Teoria do Conceito, proposta por Dahlberg (1978).

As categorias de fases da informação e aspectos essenciais estão relacionadas com a análise dos riscos de distorção. Estão vinculadas hierarquicamente por apresentarem fundamentos conceituais baseados na origem de erros e fraudes nas informações contábeis.

A categoria de afirmação é um elo entre a análise de risco e a escolha de procedimentos. Os termos dessa categoria representam os objetivos das decisões dos auditores na seleção dos procedimentos. Ao mesmo tempo estão relacionadas às características centrais que caracterizam as informações contábeis.

Os arranjos dos riscos são dados por meio da análise da descrição do risco em linguagem natural. Dessa forma, todos eles estão conceitualmente vinculados à informação contábil por três fases da informação:

\section{Reconhecimento; \\ II. Mensuração; e \\ III. Evidenciação.}

As três fases da informação se desdobram em aspectos essenciais, ou seja, patrimônio, documento suporte, valor e registro. Cada um destes aspectos vai dar origem as afirmações que, por sua vez, vão apontar para procedimentos e ciclos, completando, desta forma, os aspectos relacionais definidos para a taxonomia.

A sequência dessas etapas corresponde ao processo de análise de risco e escolha de procedimentos, porém diferente da linguagem da auditoria, agora com etapas reorganizadas traduzidas em linguagem documentária. 
A Figura 2 apresenta a estrutura de classificação da auditoria contábil na taxonomia. Cabe ressaltar que, na estrutura apresentada, há a vinculação conceitual por hierarquia entre as categorias. As demais estão organizadas conforme a classificação facetada, proposta por Ranganathan (2006) e Vickery (1960).

Figura 2 - Mapa dos aspectos relacionais na taxonomia

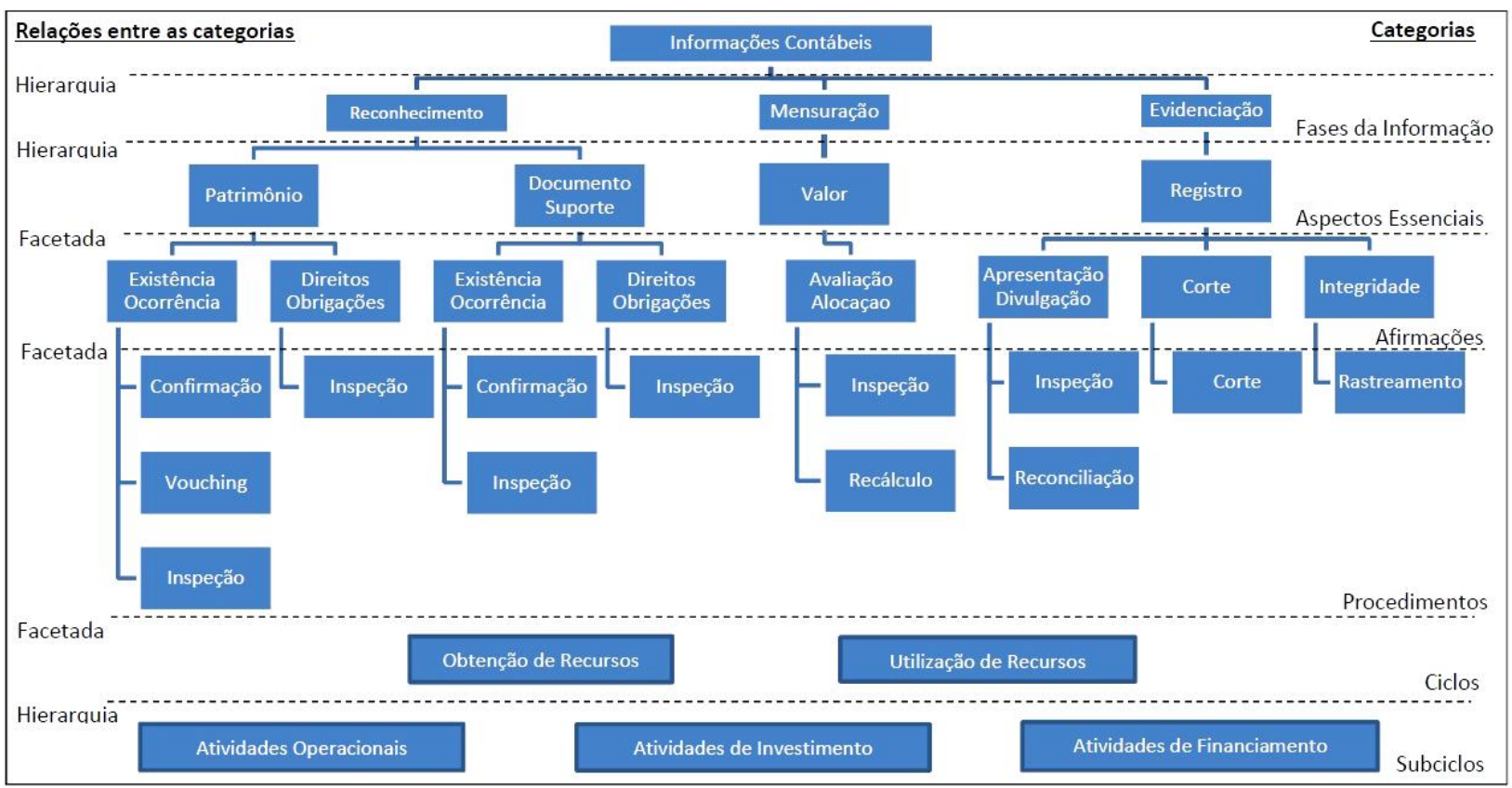

Fonte: Elaborado pelos autores

As associações entre os termos de diferentes facetas oferecem o arranjo processual da auditoria. Esses vínculos sequenciais e lógicos formam uma trilha que fundamenta e mantém o lastro das decisões sobre a escolha e aplicação dos procedimentos. As análises observaram as convergências e divergências reforçando o objetivo desse estudo com o seguinte entendimento:

- As convergências indicam a confirmação da estrutura conceitual desenvolvida; e

- As divergências são pontos de atenção e devem ser analisadas em detalhes, observando se: I. Há algum problema na estrutura conceitual; ou II. O processo de auditoria não atende às normas e conceitos levantados na literatura.

Dentre os documentos analisados há notas mencionando que essa é a primeira vez que o TCU efetua a auditoria das demonstrações contábeis em conformidade com as normas internacionais, fato que indica subjetividade implícita no relatório.

Os riscos de distorções contábeis para despesas previdenciárias obtidos nos relatórios são apresentados no quadro 2 . 
Quadro 2 - Riscos de distorção para despesas previdenciárias

\begin{tabular}{|c|c|c|}
\hline Afirmações & & Risco \\
\hline \multirow[b]{2}{*}{ Ocorrência } & R1 & Todas as despesas reconhecidas pertencem ao exercício de 2015 \\
\hline & R2 & $\begin{array}{l}\text { Ordem Bancária que não tenha correspondência com a despesa ocorrida } \\
\text { (Possibilidade de este risco ser de conta do passivo) }\end{array}$ \\
\hline \multirow[t]{3}{*}{ Integridade } & R3 & Despesa de benefício previdenciário sem o devido registro contábil \\
\hline & $\mathrm{R} 4$ & Registro contábil de despesa de exercício anterior como despesa do exercício \\
\hline & R5 & $\begin{array}{l}\text { Não contabilização da despesa com salário família e o salário maternidade feito } \\
\text { pelas empresas (com a RFB) }\end{array}$ \\
\hline \multirow[t]{2}{*}{ Avaliação } & R6 & Despesa de benefício previdenciário com valor incorreto \\
\hline & R7 & $\begin{array}{l}\text { Erro no cálculo das prestações de contas com os bancos (Este risco pode ser } \\
\text { considerado como do ativo e na categoria de afirmação de direito) }\end{array}$ \\
\hline Direitos/Obrigações & R8 & Despesa previdenciária paga indevidamente (fraude ou erro) \\
\hline \multirow[t]{3}{*}{ Divulgação } & R9 & Despesa previdenciária classificada em conta contábil incorreta \\
\hline & R10 & $\begin{array}{l}\text { Divergência entre as informações das despesas previdenciárias publicadas no } \\
\text { anuário estatístico e a contabilidade }\end{array}$ \\
\hline & R11 & $\begin{array}{l}\text { Divergência entre as informações das despesas previdenciárias publicadas no } \\
\text { Relatório de Gestão Fiscal e a contabilidade }\end{array}$ \\
\hline
\end{tabular}

Fonte: Dados da pesquisa.

A descrição do Risco 1 (R1) demonstra que o auditor está interessado em confirmar se há ocorrência de despesas do exercício auditado. Comparando com a estrutura conceitual há dois caminhos possíveis: (a) Pode ser classificado na categoria de evidenciação que abrange o atributo de tempo (período) adequado do registro e (b) $O$ fato do auditor descrever esse risco vinculado à ocorrência aponta para classificá-lo como reconhecimento. Essa possibilidade de dupla interpretação indica a presença da subjetividade no relatório de auditoria.

As duas possibilidades de classificação direcionam para testes distintos. $\mathrm{Na}$ primeira opção os procedimentos indicados serão de confirmação, vouching ou inspeção. Caso o auditor realmente esteja focado em examinar para confirmar o aspecto temporal, a taxonomia indica o procedimento de corte. Todavia, a estrutura classificatória delimita a linguagem natural, permitindo a tradução documentária. Assim, a objetividade, orientando a escolha dos procedimentos de auditoria, é dada pela estrutura taxonômica.

No caso do Risco 2 (R2), o auditor aponta o risco na categoria de ocorrência. Ao interpretar a sentença de descrição conclui-se que o auditor está se referindo a possibilidade de as despesas registradas não contarem com suporte documental adequado. Classificando esta situação na estrutura da taxonomia teremos a categoria de reconhecimento, mais especificamente em documento suporte voltado para os procedimentos de confirmação ou inspeção. Nota-se que há convergência entre a estrutura conceitual e classificação dada no relatório de auditoria. 
O Risco 3 (R3) diz respeito à integridade do registro contábil. A descrição do procedimento indicado no relatório do TCU corresponde ao conceito de rastreamento. Essa opção de classificação é a mesma da estrutura conceitual da taxonomia corroborada pelos elementos desse risco e do procedimento.

No Risco 4 (R4), a frase "registro contábil de despesa de exercício anterior como despesa do exercício" questiona se o registro do ano anterior, ao exercício auditado, foi lançado como despesa de 2015. Segundo a estrutura conceitual, essa descrição se enquadra no conceito de corte, onde o objetivo é elucidar se as despesas foram registradas no período correto. Observa-se que o relatório do TCU menciona a integridade como afirmação. Tanto a integridade quanto o corte correspondem à trilha classificatória da evidenciação e registro.

Contudo, ao comparar a descrição do risco e o conceito do procedimento, verifica-se que não há justificativa conceitual para a seleção de integridade, conforme aponta o relatório do TCU. Essa divergência indica a possibilidade de redução da subjetividade, esperada pela aplicação da estrutura conceitual da taxonomia, já que a análise comparada das informações do relatório não encontra amparo na literatura e nem nas normas contábeis.

Em relação ao Risco 5 (R5), o relatório aponta que não há contabilização da despesa com salário família e com salário maternidade, cujos pagamentos provem das empresas. Pela descrição, a classificação mais adequada aponta para a afirmação de integridade. Entretanto, no relatório não houve a menção do procedimento, mas pela trilha conceitual da taxonomia o procedimento sugerido é o rastreamento, classificação que também pode ser confirmada nos elementos textuais do relatório.

Quanto aos Riscos 6 e 7 (R6 e R7), as descrições correspondem às dúvidas sobre o cálculo ou valor da despesa onde os montantes monetários devem ser reconhecidos e apresentados no balanço patrimonial e na demonstração do resultado (mensuração). Tal evento encerra a possibilidade de erro ou fraude proveniente de um cálculo equivocado, fato que acaba por gerar um registro inconsistente (valor). Esses conceitos correspondem a afirmação: avaliação/alocação no relatório do TCU. Os procedimentos apresentados no relatório consideram a análise dos sistemas que fazem os cálculos na instituição auditada, a fim de verificar os cálculos são gerados. Tem-se, nesse caso, a coerência lógico-conceitual com a estrutura do modelo, onde os atributos indicam os procedimentos de recálculo e inspeção voltados para conferência dos cálculos. A trilha de auditoria sugerida aqui é:

Mensuração $\rightarrow$ Valor $\rightarrow$ Avaliação/Alocação $\rightarrow$
Inspeção/Recálculo $\rightarrow$ Utilização de Recursos $\rightarrow$ Valores
Utilizados com Atividades Operacionais.

O Risco 8 (R8), refere-se ao registro de uma despesa que não deveria constar do balanço. O conceito de direitos/obrigações está relacionado com a entidade que possui e controla os direitos e obrigações nela registrados. É uma questão que se relaciona com os atributos do 
patrimônio indicando direitos/obrigações no relatório e confirmado pelas bases conceituais da taxonomia, tendo a inspeção como procedimento indicado.

Os Riscos 9, 10 e 11 (R9, R10 e R11), devem ser analisados em conjunto observando suas características comuns. O R9 trata da classificação de um registro da despesa. O R10 e R11 mencionam a possibilidade de divergência entre informações de dois relatórios, o estatístico e o de contabilidade. As distorções provocadas por esses riscos afetam as informações divulgadas, incluindo notas explicativas (relatório analítico-descritivo que complementa as demonstrações contábeis). Ao analisar as descrições dos riscos observa-se que no relatório do auditor a afirmação "divulgação" é explicitada. Assim, a classificação na taxonomia é o de procedimentos de inspeção e reconciliação.

Do relatório examinado é possível depreender que as características do procedimento de inspeção de documentos são expressões identificáveis no registro relacionado ao Risco 9. Os demais, apresentam características de reconciliação de informações, comparando informações para certificarse de que foram divulgadas corretamente.

Quadro 3 - Recorte da matriz de procedimentos para despesas previdenciárias (R9 a R11)

\begin{tabular}{|l|l|}
\hline & \multicolumn{1}{|c|}{ Procedimentos } \\
\hline R9 & $\begin{array}{l}\text { Definir amostra de Ordens Bancárias emitidas pelo FRGPS, conforme cálculo constante no papel de } \\
\text { trabalho XZ, identificar as PPB's respectivas a fim de comparar a classificação contábil feito pelo Sistema } \\
\text { de Pagamento de Benefícios (Sispagben) e o Sistema Integrado de Administração Financeira do Governo } \\
\text { Federal (Siafi) }\end{array}$ \\
\cline { 2 - 2 } R10 & $\begin{array}{l}\text { Verificar se são realizados registros de conformidade de gestão da despesa previdenciária } \\
\text { previdência com os valores registrados na contabilidade }\end{array}$ \\
\hline R11 & $\begin{array}{l}\text { Comparar informações sobre as despesas previdenciárias anuais publicadas no Relatório de Gestão Fiscal } \\
\text { com os valores registrados na contabilidade }\end{array}$ \\
\hline
\end{tabular}

Fonte: Dados da pesquisa.

O uso da taxonomia para casos em que os auditores tenham pouco conhecimento sobre a instituição a ser auditada, pode ser aplicada para acessar as lições aprendidas formando um entendimento para a tomada de decisão. A partir das convergências e divergências, a Tabela 1, a seguir, foi elaborada correlacionando os resultados entre as afirmações do relatório do TCU e o modelo da taxonomia proposta. Os dados na tabela foram codificados para comparação: 1- Apresentação/Divulgação; 2Avaliação/Alocação; 3- Corte; 4- Direitos/Obrigações; 5 Existência/Ocorrência; e 6- Integridade.

Tabela 1 - Tabulação cruzada entre o Relatório do TCU e a taxonomia

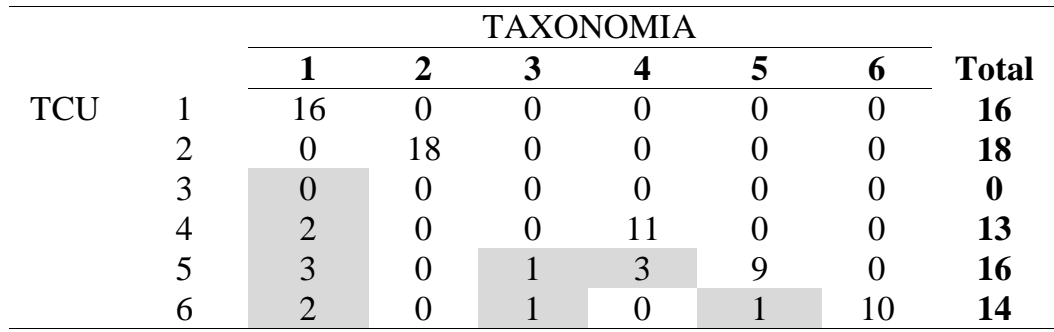




\begin{tabular}{cccccccc}
\hline Total & $\mathbf{2 3}$ & $\mathbf{1 8}$ & $\mathbf{2}$ & $\mathbf{1 4}$ & $\mathbf{1 0}$ & $\mathbf{1 0}$ & $\mathbf{7 7}$ \\
\hline \multicolumn{4}{c}{ Fonte: } & Elaborado pelos autores.
\end{tabular}

Além das despesas, a matriz de risco da receita e do imobilizado também foram analisadas. No total de 77 riscos observados no relatório do TCU apenas 13, ou seja, $16,88 \%$ do total foram divergentes em relação às sugestões de classificação previstos na taxonomia. As divergências identificadas correspondem à generalização nas descrições dos riscos nos relatórios de auditoria, situação que pode favorecer a subjetividade na decisão.

Por outro lado, as divergências corroboraram a capacidade do modelo em direcionar a escolha de procedimentos para redução da subjetividade. Isso é percebido ao verificar que a linguagem documentária influencia a decomposição dos conceitos relacionados com as descrições de riscos coletadas em linguagem natural, classificando-as em uma estrutura padrão que serve de base para recuperação das informações sobre lições aprendidas. Antes de qualquer afirmação, cada divergência foi analisada e em todos os casos observou-se a contradição nos relatórios sobre os riscos com os procedimentos ou afirmações selecionadas que permitiram a identificação de possibilidades de melhoria no relatório.

Considerando que a taxonomia como linguagem documentária favorece a recuperação da informação, conforme preconizam Sousa e Araújo Júnior (2013), a taxonomia aqui proposta pode apoiar na seleção de uma trilha de identificação de riscos e a escolha de procedimentos, recuperando itens informacionais constantes nos documentos que apoiam a auditoria. Em outras palavras, o grau de precisão nas decisões do auditor está vinculado à padronização da linguagem, que pode ser comparado com o grau de precisão na recuperação de informações citado pelos autores. Um vocabulário controlado, onde o auditor terá opções objetivas para escolha dos procedimentos, poderá minimizar a subjetividade das decisões.

As convergências $(83,12 \%$ dos casos registrados no relatório do $\mathrm{TCU}$ ), reforçam a possibilidade de uso da taxonomia por auditores, já que a sua estrutura está calcada em uma linguagem documentária que possui regras, padrões e relações lógicas entre os termos de classificação. Sendo assim, a estrutura da taxonomia apresentada comporta lições aprendidas que podem ser atualizadas periodicamente. Ao analisar um determinado risco para classificá-lo na estrutura, tem-se a tradução da linguagem natural do auditor para a linguagem documentária. Dessa maneira, as informações de lições aprendidas são armazenadas e podem ser recuperadas pelos auditores e demais usuários da informação contábil.

\section{Considerações finais}

Ao analisar a aplicabilidade da taxonomia de distorções contábeis é perceptível a sua funcionalidade como instrumento de redução da subjetividade nos processos de auditoria contábil. Além disso, a sua aplicação na análise de documentos obtidos junto ao Tribunal de Contas 
da União permite inferir que esse formato de linguagem documentária auxilia na escolha de procedimentos com base na análise de risco de distorções provocados por erros ou fraudes. As sequências lógicas entre os conceitos ligados a cada termo evidenciam trilhas de auditoria, sugerindo a redução da subjetividade nas escolhas do auditor.

As divergências pontuais entre o relatório do auditor e a estrutura conceitual foram analisadas, fato que ensejou o reexame das relações conceituais para verificar se o problema é oriundo da estrutura da taxonomia ou do relatório. Não obstante, ao aplicar a taxonomia nesses casos observa-se o direcionamento das decisões lastreadas nas relações lógicas conceituais. Mesmo considerando o pouco conhecimento sobre a instituição a ser auditada mencionada anteriormente, é notório que os auditores do TCU são capacitados, porém as divergências foram oportunas para o estudo empreendido. Na tabulação cruzada as convergências em $83,12 \%$ dos casos confirmam a factibilidade da taxonomia como estrutura conceitual reflexo da prática da auditoria. Ao coletar, na linguagem natural, os termos que representam os riscos de distorções e classificálos, ficaram evidentes as trilhas de auditoria, que por sua vez, podem apoiar o processo de busca e recuperação da informação contábil.

\section{Referências}

AMERICAN INSTITUTE OF CERTIFIED PUBLIC ACCOUNTANTS. Evolution of auditing: from the traditional approach to the future audit. New York: AICPA, 2012. Disponível em: https://www.aicpa.org/interestareas/frc/assuranceadvisoryservices/downl oadabledocuments/whitepaper evolution-of-auditing.pdf. Acesso em: 28 mar. 2019.

BARDIN, L. Análise de conteúdo. Lisboa: Edições 70, 1977.

BRANDES, A. F. et al. Diretrizes para Construção do Tesauro da Rede Virtual de Bibliotecas - Congresso Nacional - RVBI. Brasília: Senado Federal/ Secretaria de Bibliotecas, 2007.

BOYNTON, W. C.; JOHNSON, R. N.; KELL, W. G. Auditoria. 7.ed. São Paulo: Atlas, 2002.

CASTRO, D. P. de. Auditoria, contabilidade e controle interno no setor público: integração das áreas do ciclo de gestão: contabilidade, orçamentos e auditoria e organização dos controles internos, como suporte à governança corporativa. 3 ed. São Paulo: Atlas, 2010.

CHAN, R. W. The value investors: lessons from the world's top fund managers. Singapore: John Wiley \& Sons, 2012.

CHANG, S. et al. The development of audit detection risk assessment system: using the fuzzy theory and audit risk model. Expert Systems with Applications, v. 35, n. 3, p. 1053-1067, oct. 2008. Disponível em: https://www.researchgate.net/publication/221996825 The development 
of audit detection risk assessment system Using the fuzzy theory an d audit risk model. Acesso em: 29 mar. 2019.

CONSELHO NACIONAL DE JUSTICA - CNJ. Modelo de Requisitos para Sistemas Informatizados de Gestão de Processos e Documentos do Judiciário Brasileiro MoReq-Jus. Brasília: 2009.

DAHLBERG, I. Teoria do conceito. Ciência da Informação, v.7, n.2, p.101107, $1978 . \quad$ Disponível em: http://revista.ibict.br/ciinf/article/view/115/115. Acesso em: 21 mar. 2019.

GOVERNMENT ACCOUTABILITY OFFICE - GAO. Content analysis: a methodology for structuring and analyzing written material. Washington, 1996. Disponível em: http://www.gao.gov/products/PEMD-10.3.1. Acesso em: 29 mar. 2019.

GIESS, M.; McMAHON, C.; BOOKER, J. D.; STEWART, D. Application of faceted classification in the support of manufacturing process selection. Journal of Engineering Manufacture, v. 223, n. 6, p. 597-608, 2009.

GUEDES, W. ARAÚJO JÚNIOR, R. H. de. O fluxo de informações na auditoria pública e a teoria Matemática da Comunicação. Encontros BIBLI, v. 19, n. 40, p.33-50, mai./ago., 2014. Disponível em: https://periodicos.ufsc.br/index.php/eb/article/view/1518-

2924.2014v19n40p33/27574. Acesso em 29 mar. 2019.

HSIAO, Y. An audit-based prediction model for aviation maintenance safety. New York: Faculty of the Graduate School of the University at Buffalo, 2011. (Tese de Doutorado).

LONGO, C. G. Manual de auditoria e revisão das demonstrações financeiras: novas normas brasileiras e internacionais de auditoria. São Paulo: Atlas, 2011.

LOUGHRAN, Marie. Auditing for Dummies. Hoboken: Wiley, 2010.

MILNE, C. Taxonomy development: assessing the merits of contextual classification. Records Management Journal, Bingley, v. 17, n. 1, p. 7-16, 2007.

MUELLER, S. P. M. Métodos para pesquisa em ciência da informação. Brasília: Thesaurus, 2007.

RANGANATHAN, S. R. Colon classification: basic classification. Bangalore: Ess Publications, 2006.

SOUSA, R. T. B. de.; ARAÚJO JÚNIOR, R. H. de. A classificação e a taxonomia como instrumentos efetivos para a recuperação da informação arquivística. Ciência da Informação, Brasília, DF, v. 41, n. 1, p.148-160, jan./abr. 2013. Disponível em: http://revista.ibict.br/ciinf/article/view/1400/1578. Acesso em: 28 mar. 2019. 
VICKERY, B. C. Faceted classification: a guide to construction and use of special schemes. Londres: Aslib, 1960.

VITAL, L. P.; CAFÉ, L. M. A. Práticas de elaboração de taxonomias: análise e recomendações. In: ENCONTRO NACIONAL DE PESQUISA EM CIÊNCIA DA INFORMAÇÃO, 8., 2007. Salvador: [Anais...]. Salvador: PPGCIUFBA, 2007. p.1-16. Disponível em: http://www.enancib.ppgci.ufba.br/artigos/GT2--141.pdf. Acesso em 29 mar. 2019.

WALDEN, C. T. A taxonomy based assessment methodology for small and medium size manufacturers. Starkville: Faculty of Mississippi State University, Mississippi State University, 2007. (Tese de Doutorado). 